\title{
Urbanization, Work and Community: The Logic of City Life in the Contemporary World
}

DOI: 10.12776/QIP.V21I1.785

\author{
Allen J. Scott \\ Received: 9 September 2016 Accepted: 2 November 2016 Published: 30 April 2017
}

\begin{abstract}
Purpose: I initiate the discussion with a statement about cognitive-cultural capitalism and its concentration in large global cities. This is followed by an argument to the effect that the specificity of the city resides in the manner in which the diverse social phenomena that it contains are brought into a composite pattern of spatial integration. With these preliminaries in mind, I examine the economic structure of the city in cognitive-cultural capitalism, with special reference to the emergence of a new division of labor and the changing configuration of intra-urban production space. This account leads directly to consideration of the restratification of urban society and its effects on neighborhood development and social life. The final section of the paper picks up on the notion of the Common in cognitive-cultural capitalism and offers some speculative remarks regarding the implications of this phenomenon for the economic and social order of cities.
\end{abstract}

Methodology/Approach: Historical and geographical narrative combined with appeals to the theory of political economy.

Findings: Cognitive-cultural capitalism is emerging as a dominant force of social and economic change in the twenty-first century. This trend is also evident in new patterns of urbanization that are emerging on all five continents. These patterns reflect dramatic shifts in the structure of urban production systems and the significant restratification of urban society that has been occurring as a consequence.

Research Limitation/implication: The paper is pitched at a high level of conceptual abstraction. Detailed empirical investigation/testing of the main theoretical points outlined in the paper is urgently called for. 
Originality/Value of paper: The paper offers an overall theoretical synthesis of the interrelationships between cognitive-cultural capitalism and processes of urbanization.

Category: Research paper

Keywords: capitalism; cognitive-cultural economy; Common; global cityregions; urbanization

\section{THE HISTORICAL CONTEXT}

I seek to address some basic questions about urbanization in the twenty-first century, with particular reference to the new forms of work and life that are emerging in large cities all over the world but most of all in the advanced capitalist economies of North America, Western Europe and Eastern Asia.

The economic logic of capitalism revolves centrally around a process of accumulation, namely, an incessant drive to reinvest the profits from production, hence inducing continual but intermittent rounds of development and growth. Accordingly, the technological foundations, sectoral make-up, norms of market competition, labor relations, and locational alignments of capitalism also go through many shifts in form and substance. Definite combinations of these variables sometimes stabilize for longer or shorter historical periods in identifiable socio-technical phases of development or regimes of accumulation. These phases are not always clearly differentiated from one another, but three particular cases are noteworthy for their distinctiveness as well as for the specific patterns of urbanization associated with them (Scott, 2011). The water- and steam-driven mills characteristic of the classical factory and workshop system in Britain in the nineteenth century gave birth to the traditional working-class industrial town. The fordist mass production system that reigned in the period from the beginning of the twentieth century down to the 1960s and 1970s lay at the core of the metropolitan areas of the Manufacturing Belts of North America and Western Europe. Since the end of the twentieth century a new species of capitalism founded on digital technologies and a labor force of highly-qualified intellectual workers has been gathering momentum and is bringing in its train some remarkable new shifts in the form and substance of urbanization.

The new capitalism emerged out of the ruins of the mass production system at the end of the twentieth century, and was initially identified as a "post-fordist" regime of accumulation. This designation is still in wide use, but has been giving way in recent years to more affirmative labels that identify early twenty-first century capitalism in terms of its basic digital technologies, its proliferating network structures of economic and social life, its foundations in the cerebral and affective human capital of the workforce, and its apparent capacity to generate high levels of economic and social innovation. Perhaps the most dramatic sign of the advent of this regime was the changeover from the dominant electro-mechanical technologies of fordism to the computerized modes of 
productive activity that became common after the late 1970s. This transformation made it possible to automate swaths of standardized and algorithmic work across virtually all sectors of the economy and to bring an enormous number of new and upgraded products onto the market. Equally, the introduction of computerized technologies into the workplace had the effect of magnifying the capacities of intellectual labor by augmenting the cognitive and cultural talents of the individual worker by means of the exceptional powers of calculation, information management, and communication unleashed by digitization. For this reason, I have suggested elsewhere that the term "cognitive-cultural capitalism" represents an especially appropriate way of referring to the new economic and social arrangements that are taking shape on all sides today. This term has the merit of referring explicitly to the fundamental role of both cognition and culture in the foremost segments of productive work in the capitalism of the early twenty-first century. As such, it also refers by implication to a core group of sectors focused on outputs such as high-technology devices, software, advanced financial and business services, and symbolic-cum-experiential products such as film, music, electronic games, and fashion, all of which depend in important ways on labor inputs marked by high levels of intellect and empathy, and all of which have strong proclivities to locate in major urban areas.

\section{WHAT IS THE CITY?}

As a matter of principle, we may begin with the proposition that cities are everywhere and always phenomena whose form and functions mirror the wider social formations within which they are embedded. This organic relationship is bound up with the necessary spatiality of all social outcomes, and above all with the deeply-rooted urge in countless kinds of human activity to converge together in dense geographic clusters. This urge is especially robust in capitalism, which can only be efficiently (i.e. profitably and competitively) organized when selected groups of producers agglomerate together in association with adjacent labor markets. In the purely analytical as opposed to historical order of enquiry, what we might call "proto-urban clusters" materialize in this way, though they only become recognizably urban as a host of other social phenomena, such as residential neighborhoods, transport networks, shopping districts, and relevant arrangements of collective action are also brought within the vortex of agglomeration. In a more historical order of enquiry, urban development is manifest as a path-dependent process in which cities evolve through recursive marginal accretions of new economic and social substance over time. In this manner, cities in capitalism emerge from the social and property relations of the prevailing regime of accumulation. Cities, however, do not simply spring forth as dependent excrescences of the regime of accumulation, for they play a critical role in the social reproduction of capitalism, not only by promoting economic efficiency and competitive advantage, but also by securing continuity of social life and labor market relationships via their built forms and physical infrastructures. 
As argued at length in Scott and Storper (2015) these fundamental aspects of cities in capitalism are reflected in intra-urban processes that in the first instance can be understood in terms of an abstract logic revolving around the notions of density and proximity within an agglomerated mass of social and economic activities. In the second instance, they are expressed in patterns of land use and associated human interactions as represented by conjoint production, residential and circulation spaces forming an urban land nexus, i.e. the internal functionally integrated fabric of the city. These essential attributes of urbanization, together with their dependent daily and weekly rhythms of human mobility, constitute the essential specificity of the city in capitalism and separate it as a sui generis object of study from the rest of society. The city, then, is a network of many and sundry undertakings that are urban by virtue of their mode of spatial integration into a nexus of interdependent polarized land uses; and while networks of this sort are never bounded by a precise outer boundary, they are nonetheless always recognizable by reason of their endogenous locational and functional interactions relative to a dominant centre of gravity. Furthermore, given their dense, polarized, and spatially integrated character, cities are foci of massive land rent generation and they are thus also major arenas of what Harvey (1978) has identified as critical secondary circuits of monetary and financial flow. In view of these diverse attributes of urbanization in capitalist society, cities are invariably sites of social conflict focused on the problems, predicaments, and injustices that grow out of the tensions internal to this peculiar mode of spatial integration and that partly shape the urban question as a circle of scientific and political concerns.

That said, we still cannot properly identify the urban question in the current conjuncture without also considering three important fields of action representing the framework of institutional order and political contestation in the cities of contemporary capitalism. In the first place, firms and households constitute a domain of civil society in which decision-making and behaviour are individualized, rooted in private property, and regulated by markets. In the second place, this domain of purely private interests is complemented by formal and informal agencies of governance and coordination with mandates to address urban problems and to manage the course of local development by means of collective action. In the third place, a distinctive communal arena, or Common, springs from the shared character of urban life. The Common is a form of social reality that lies beyond the bounds of individual private ownership, though it may be encroached upon by private interests and it is frequently regulated by agencies of governance with powers to extend or limit its contents and range. Thus, at any given moment in time there are always deeply seated political collisions between those elements of civil society that want to appropriate parts of the Common for their own private use and those that want to preserve or enhance it as a free and open asset. Since the Common has special and expanding influence in the cities of cognitive-cultural capitalism some further commentary on this topic is apposite at this stage. 
In a first round of identification, the Common can be described as an interlocking amalgam of externalities, resources, and cultural or intellectual assets that accrue to the city and that are freely available to all. A more extended definition would include different kinds of joint property regimes as proposed by Ostrom (2010), where selected groups of citizens dispose of so-called "common-pool resources" from which others are excluded. In the present paper we will be concerned with cases of both types, but with a clear emphasis on the former where ownership restrictions of any sort are entirely non-existent. The contents of the Common are extremely heterogeneous, comprising as they do various kinds of spillover effects, tangible and intangible resources such urban infrastructures or local economies of scale and scope, and a sort of free-floating protoplasm composed of information, knowledge, behavioural codes, and traditions, and while they frequently have beneficial effects, they can also impose social costs as in the case of polluted air or congested streets. The important point is that the benefits and costs of the Common are privately absorbed but do not involve countervailing payments for value received or compensation for any injuries undergone. The whole can be seen as a Common by analogy with the Common or waste land that was open to all members of the village community for pasturing livestock in the agricultural economy of pre-Enclosure England. Moreover just as the traditional Common was subject to the risk of overgrazing, many but by no means all of the benefits of the urban common today are susceptible to exhaustion by overexploitation so that decisive collective remediation is often required to restore at least some of its positive value.

The conventional view of the Common is that it constitutes a realm of market failure, as for example in urban areas where positive and negative spillover effects circulate through the city without benefit of market mediation, or where public goods are supplied in order to secure the continued urban viability. A related and explicitly marxian line of attack focuses on the Common as a field of "general intellect," i.e. a source of freely-circulating epistemic assets, and above all useful knowledge inputs to private firms (see, for example Moulier Boutang, 2007). A more general definition is provided by Hardt and Negri (2009, p.251) who identify the Common in the context of the city as a spatial concentration of "people living together, sharing resources, communicating." A vast extension of the Common has taken place over this last couple of decades as a direct effect of the development of cyberspace, and this new facet of social reality is pregnant with implications for all aspects of urban development in the context of intensifying globalization.

\section{THE ECONOMIC CONSTITUTION OF THE CITY}

Despite occasional claims to the effect that the final paroxysm of capitalism is just over the horizon, it continues to evolve irregularly forward in recurring waves of spatial intensification and spread. In its latest incarnation as a cognitivecultural socio-economic formation, capitalism has not only become insistently 
global, but has also deepened its roots in large metropolitan areas. This is not to say that capitalism has been taken over in its entirety by cognitive-cultural forms of production and work activity, or that it is based solely in large cities. That said, the leading edges of growth, innovation, and economic transformation in contemporary society are emphatically concentrated in the sectoral formations identified in the first section of this paper as constituting the core of the cognitive-cultural economy, and these are located in city-regions all across the world, with places like New York, Los Angeles, London, Paris, Tokyo, Shanghai, Singapore, Bangkok, Mexico City, and Buenos Aires, to mention only a few, clearly in the vanguard. Cities like these are the principal motors of global capitalism in the twenty-first century.

The leading sectors of this new economic order are drawn to city-regions by reason of their multiple interdependencies and labor market needs as well as by their proclivity to generate significant learning, creativity and innovation effects (including entrepreneurship) when they locate jointly in spatial agglomerations. Firms in these sectors actually cluster together not just at the broad level of the individual city but also at a much more detailed level within intra-urban space where they form what earlier generations of economic historians and geographers, such as Allen (1929), called specialized "industrial quarters." The factors underlying this tendency to agglomeration have been investigated by numerous regional development theorists, and may be summarized in three key points.

- Units of production in the cognitive-cultural economy frequently work together in many-sided networks. The efficiency of these networks is in numerous instances enhanced when the parties involved are located in close proximity to one another, especially when transmission of tacit knowledge by means of face-to-face dialog is common.

- Firms in the new economy typically employ workers endowed with intellectual and creative skills. A large pooled supply of these workers at locations adjacent to workplaces is an essential complement to production.

- Information exchanges between firms in cognitive-cultural production clusters tend to enhance know-how, and thus help to stimulate informal innovation. This tendency is manifest in the relatively high levels of patenting that characterize large urban areas today (Feldman and Florida, 1994; Ó'hUallacháin, 1999).

These three sets of variables, together with the physical infrastructure of the city, not only reinforce agglomeration but also constitute critical foundations of the competitive advantages of any given centre. As such, they have always played a significant though variable role in processes of capitalist urbanization, and especially in the new economy where so much of the production system is marked by high levels of vertical and horizontal disintegration, where labor markets are splintered into many different niches, and where informal innovation is an important mechanism of product and process change. The play of these 
variables is such that the more any cluster grows the greater the stock of agglomeration economies that partly constitute the Common. To be sure, diseconomies are also invariably generated by growth, but when these significantly threaten overall efficiency, agencies of collective action typically intervene to dampen their negative effects. On these bases, large cities and cityregions in many different countries function as communal springboards facilitating the capacity of producers in the cognitive-cultural economy to contest national and global markets.

There is, however, another side to this image of success, for the same cities and city-regions in cognitive-cultural capitalism almost always abound with large cohorts of low-wage and politically-marginalized service workers. Unlike the old urban working class in the cities of fordist capitalism, these workers are not primarily employed in manufacturing industry. Rather, they are pre-eminently engaged in occupations like taxi-driving, restaurant work, janitorial activities, para-medical functions, home repair, gardening, and child-minding, to mention only a few exemplary cases. Their principal role in these occupations is to sustain the infrastructures and facilities of the urban system and to support the domestic and personal needs of the more affluent fractions of the citizenry. Occupations like these are notorious for their low and generally decreasing wages as well as for their extreme precariousness. Still, and even if low-wage service workers usually lack formal qualifications, it would be incorrect to suppose that they are devoid of meaningful cognitive-cultural capabilities, for they are frequently called upon to exercise much discernment, resourcefulness, self-awareness, and flexibility in the fulfilment of their jobs. Indeed, precisely because these jobs require considerable initiative on the part of the labor force and also frequently entail a negotiated interface with others, they cannot (unlike routine manufacturing activities) be consolidated into large standardized units of operational activity and dispatched to low-wage locations in the world periphery.

The two-speed employment systems that characterize large cities in capitalism today thus operate not as functionally separate worlds, but as the interdependent units of a unified whole. On the one side, high-level cognitive-cultural workers in these cities are engaged in the production and commercialization of contrived outputs for world-wide markets. On the other side, a host of low-wage service workers in the same cities secure the essential social and economic conditions under which the upper half of the system is able to function effectively. A vivid illustration of these remarks can be discerned in the division of labor in and around the gleaming office towers of the financial districts of London, New York, and Tokyo where one army of extravagantly-paid employees is engaged during the daytime in high-profile business and financial operations, while at night another army composed of minimum-wage workers takes over in order to prepare the same buildings for the next day's work.

In the more skilled and highly-paying reaches of the urban economy, firms tend to play insistently on product registers involving short runs of output (sometimes customized) with exclusive quality, performance, and design attributes. These 
product qualities are often firm-specific in that they reside in the expertise of the individual firm, but they may also have place-specific features that reflect the unique traditions, craftsmanship, and reputational assets embedded in the urban Common. Examples of products that bear the stamp of their place of origin are motion-pictures in Hollywood, aerospace in Toulouse, financial services in London, and haute couture in Paris. In each of these cases, localized concentrations of technical know-how and human sensibility occupy an important place in production and hence in helping to ensure the competitiveness of outputs. Products with unique features like these are also susceptible to legal safeguards offering protection from competition by means of copyright, trademarks, certificates of geographic origin, and other forms of branding.

Because of their often idiosyncratic firm- and place-specific traits, and no matter whether they depend on explicit legal protection or not, the products of the new economy increasingly face one another on markets that are subject to the rule of monopolistic or oligopolistic competition as formulated by Chamberlin (1933). Goods and services that compete in this way are generically similar to one another, but are differentiated by their detailed design specifications such that each firm- or place-specific product commands a distinctive market niche. Thus, while it is entirely correct to affirm that economic competition has become greatly intensified under contemporary conditions of globalization and neoliberal policy orthodoxy, this is far from representing a wholesale return to traditional laissez-faire. For the same reason, there are grounds for scepticism in regard to the analysis proposed by Rifkin (2014) who conjectures that digital technologies and the Internet of Things (including three-dimensional printing) are leading to the emergence of a society in which positive prices will virtually disappear because the possibility of reproducing unlimited quantities of outputs at close to zero marginal cost is imminent. Rifkin (2014) suggests that a kind of collaborative Common will steadily supplant competitive capitalism and that this will then lead on to the formation of an extensive sharing economy. This idea finds an echo in the work of Benkler (2003) who argues that the Internet will eventually liberate the production of culture and information from commercial interests. A further echo is to be found in the more politically radical theses proposed by Vercellone and Negri (2008) to the effect that general intellect is now maturing to the point where it heralds the advent of new modalities of production and value and the imminent emergence of an extended logic of social cooperation. There is, to be sure, a very unstable boundary between the digital Common on the one hand, and private producers with their portfolios of intellectual property rights on the other, but some tempering of these speculative arguments about the radical retreat of capitalism is surely in order. Thus, whereas cooperation, sharing, and open-source inputs to production and social life are unquestionably pushing the boundaries of the Common outwards, the equally dramatic upsurge of Chamberlinian competition, branding, and intellectual property regimes in all their different forms means that private firms, no matter how much they are caught up in the Common, can exert varying degrees of monopolistic or oligopolistic market control and thus can extract positive prices 
from consumers even in the extreme case of zero marginal cost. Much of the digital realm, in any case, can only be accessed by means of web sites and applications created and held by private profit-making firms with established intellectual property rights, and increasing numbers of these firms have significant ownership advantages. In a word, and for the reasons adduced, any claims about the deliquescence of the individual capitalist firm under pressure from an expanding Common must remain extremely theoretical to say the least, especially given the fact that the Internet itself is daily opening up an enormous number of new entrepreneurial opportunities.

A more evident consequence of the widening diffusion of digital technologies in capitalist society is the weakening of the forces of agglomeration in at least some sectors of the economy. As communications networks with embedded computers become ever more powerful, any need for complementary producers to locate in close proximity to one another is apt to be diminished by the substitution of electronic interactions for more personalized encounters. The net effect, all else being equal, is that many firms find it increasingly attractive to relocate in more decentralized, lower-cost locations. Similarly, improved digital technologies facilitate communications between the different internal departments of given firms, thereby opening up potential future scenarios of accelerated geographical disintegration not to mention vertical and horizontal disintegration in the corporate economy, conceivably making it possible for fragmented units of production to boost their command of Chamberlinian monopoly powers via increasing specialization and individuation. Still, as Taylor, et al. (2013) suggest, the spatial fragmentation of corporate functions (notably in the advanced business and financial services sector) frequently leads not so much to unbridled dispersal as it does to the allocation of different units of the firm to different urban agglomerations. For the present, at least, the leading sectors of contemporary capitalism continue overwhelmingly to cluster in major cities, which in their turn continue to develop and grow apace. This persistent urban expansion is also partly sustained by the tendency of the cognitive-cultural economy to give birth to new sectors of production that help to maintain a rising tide of agglomeration forces.

Precisely because of this unrelenting pattern of growth, large cities in contemporary capitalism have become vortexes of rent generation and upwardly spiralling land prices, a phenomenon that has been much accentuated of late by the steady internationalization of property speculation. More to the point, land rent is generated collectively out of the dynamics of the Common (i.e. as an effect of relative location) but is privately appropriated by individual property owners. At the same time, the resurgence of land rents in the principal cities of cognitive-cultural capitalism is bound up with striking changes in urban skylines, above all in central business districts where the advanced financial, banking, and business service activities of the new economy are typically concentrated. Not the least of the discernible changes occurring in the central areas of these cities is the insistent intensification of land uses via the constantly increasing height and 
density of buildings. As Sklair (2010) has observed, the grandiloquent architecture of a large proportion of these buildings offers a sort of symbolic reflection of the bombastic spirit of the international corporate organizations that occupy them. Moreover, rent in the cognitive-cultural economy is by no means confined to land, but is also now prominent in the sphere of production, for the rise of Chamberlinian competition has made it increasingly possible for firms to earn significant super-profits on their outputs, and these are in important respects coming to displace normal profits as the main source of revenue from production in many segments of the new economy.

\section{THE SOCIAL CONSTITUTION OF THE CITY}

Much has been made in recent years about the formation of a new plutocracy the one-percent - in contemporary capitalist society, and much political protest has been justifiably directed at the spectacularly widening income inequalities that are the principal symptom of this condition. Yet as serious as this situation may be, and notwithstanding its insistent documentation in the media, it tends perhaps to obscure a much more pervasive social divide in contemporary urban society between high-wage cognitive-cultural workers on the one hand and lowwage service workers on the other. A bipartite social cleavage has always existed between the upper and lower income groups in capitalist cities, but it has become greatly accentuated of late years as the cognitive-cultural economy has taken firm hold over urban affairs.

In the immediate post-War decades, in North America and Western Europe, the fundamental division of labor in production was identifiable in terms of a cohort of white-collar managerial, technical and professional workers on the one side, and a cohort of blue-collar manual workers on the other. This twofold split was in turn replicated in the social and physical fabric of the metropolis where it assumed, incompletely but distinctly, the form of a spatial partitioning of neighbourhoods, marked on each side by distinctive processes of family life and social reproduction. Today, as the cognitive-cultural economy moves ahead, a very different division of labor and a corresponding restratification of urban society - together with a derivative spatial division of neighbourhoods -- are making their historical and geographical appearance in major cities. For one thing, the highly-qualified and (usually) highly-paid workers who constitute the prestigious upper tiers of the cognitive-cultural labor force can no longer be described as being equivalent to the bureaucratic/professional white-collar fraction typical of fordism. To an even lesser extent can they be cast as a troop of conformist organization men (cf. Whyte, 1957). Rather, the upper tier now constitutes a new kind of class formation made up of men and women variously endowed with high levels of human capital in regard not only to functions such as analytical thinking and judgment, but also fluency of ideas, social perceptiveness, flexible attitudes, imaginativeness, aesthetic sensibility, and capacities for interaction with others, as well as substantive knowledge and 
expertise in fields such as technology, medicine, business, policy analysis, and the arts (cf. Gouldner, 1979). For another thing, low-wage service workers are now replacing the blue-collar production workers who once dominated the lower half of society in large capitalist cities. These service workers are a major element of the new economy where they perform crucial but poorly-paid tasks that underpin the social reproduction of the upper half of the labor force and that help to maintain the functional fabric of the city. Hence they constitute what we might refer to as a "new servile class," a designation that is underscored by their precarious job prospects, and, in so many cases, by their status as socially marginalized immigrants from the peripheries and backwaters of global capitalism. The bottom end of this class gives way in numerous cities to an underclass of casual day workers, street vendors, the long-term unemployed, the unemployable, the homeless, and the chronically ill who, as Standing (2011) has noted, eke out a precarious living on the fringes of urban society and who, in the burgeoning metropolitan areas of the Global South often constitute a disconcertingly large fraction of the total population.

Above all the generally elevated and relatively secure remuneration of high-level cognitive-cultural workers contrasts sharply with the low and much more precarious wages of the new servile class. For example, in Los Angeles County in the year 2012, the ratio of the median wage and salary income of a representative group of cognitive-cultural workers to a representative group of low-wage service workers was just above six to one (cf. Scott, 2012). This is a high multiple by any standard, and the fact that it is based on aggregate measures certainly conceals a significant range of more extreme cases. Indeed, the true multiple is probably considerably higher than six to one since much information for illegal immigrants -- who are strongly represented in the new servile class -is not captured in official statistics. Moreover, with the increasing prevalence of two-income families in advanced capitalist societies absolute differences in family income between the upper and lower halves of the labor force are greatly magnified, and this translates in turn into notably widened differences with respect to life chances and the quality of overall social life. A marked consequence of this state of affairs is that the children of high-level cognitivecultural workers are typically socialized -- in their families, in their neighbourhood schools and communities, and in adjoining urban spaces -- into a highly privileged set of expectations and prospects. The children of the new servile class, by contrast, are much less favoured, and they face many more hurdles in any effort to gain access to the higher echelons of society. There are profound generational implications in this condition, not only in terms of the reinforcement of the great income divide in twenty-first century cities, but also in terms of the differential social and psychic rewards of urban life for members of the upper and lower occupational strata, especially where these differences intersect with racial identities.

These inequalities in urban society are compounded by the educational system at all levels of instruction. Primary and secondary schools located in rich and poor 
urban neighbourhoods typically display wide variations in the matter of teacher quality and pedagogical practices, and this alone results in substantial social discrepancies, especially concerning access to university-level education and the credentials required for entry into well-paid professional work. Access to advanced education is all the more important because colleges and universities are becoming more and more attuned in their teaching pursuits to the needs of the new economy (and in many cities this means adaptation to the needs of the local economy). A signal indicator of this intensifying trend is the accelerated growth of professional-education programs in universities and allied institutions in fields as diverse as engineering, medicine, law, public health, business, information studies, journalism, public policy, social work, film and television, and architecture, to mention only some of the more obvious cases. This turn to vocational training - frequently at the expense of more critical modes of enquiry -- is an indication of the increasing focus in institutions of advanced education on turning out certified individuals who are then able to move more or less seamlessly into the cognitive-cultural labor force as technocrats, managers, policy analysts, health specialists, human resources workers, cultural intermediaries, and all the rest. Coin (2013) has referred to this development in terms of the "neoliberal reform" of higher education in the twenty-first century. The same neoliberal logic is evident in the proliferation of money-spinning branch-plant campuses deployed by universities in the global North to major cities in the global South.

All of these changes are profoundly interwoven with many visible adjustments in the social geography of the urban milieu. They are especially manifest in the restructuring of residential space that has been occurring in North American and Western European cities in the context of the demise of fordism and the upsurge of cognitive-cultural capitalism. Perhaps the most striking instance of these adjustments is the insistent colonization by high-level cognitive-cultural workers of residential areas close to the centre of the city. Large numbers of these workers continue to live in their traditional habitat in suburbia, but many have been increasingly settling in gentrified central-city neighbourhoods in recent decades. Gentrification has been accompanied by the out-migration of large numbers of the low-wage residents - including the remnants of the old bluecollar working class - who in the United States and many countries of Europe traditionally occupied the majority of central-city neighbourhoods. Much of this out-migration can be accounted for by the disappearance of nearby manufacturing jobs, but much of it is also due to inflation of housing prices as high-level cognitive-cultural workers have increasingly moved into residential districts close to downtown areas. The most vulnerable low-wage residents of these districts - i.e. those occupying rental accommodation - have been particularly burdened by rising real estate values. Numerous families that formerly lived in the urban core have thus been under considerable pressure to relocate to other areas, notably to nondescript neighbourhoods in intermediate zones of the city and to those parts of suburbia where cheap housing is available. 
The trends described above reflect the comprehensive social restratification that has occurred in major cities of cognitive-cultural capitalism of late, though this does not tell the whole story. In addition, we must carefully weigh the effects of the changing economic character of central city areas. Above and beyond the loss of manufacturing jobs in these areas there have been enormous increases in employment opportunities for high-level cognitive-cultural workers as advanced sectors such as finance, business services, media, advertising, and fashion and design have grown apace at central city locations. Recent rounds of expansion of high-wage jobs at these locations have stimulated the demand for locallyaccessible housing by well-paid cognitive-cultural workers, especially those with demographic profiles like young professionals, cohabiting couples, metrosexual singles, two-income middle-class households, people in same sex unions, and apartment sharers (Haase, et al., 2010). Concomitantly, the qualitative attributes of many inner-city residential areas have been transformed by relentless rehabilitation or reconstruction of the local housing stock and by public investment in local amenities. The growing presence of high-income residents in inner city areas has also stimulated the growth of shopping, entertainment, and cultural facilities so that there is an increasing interpenetration of the spaces of work, social reproduction, and leisure in these parts of the city. This trend provides a sort of echo in urban space of what, according to Fumagalli (2011), can be seen as the increasing erasure of the difference between work-time and life-time in the space of personal existence in capitalism today.

To be sure, sundry analysts -- probably the majority -- invoke the rent-gap theory devised by Smith (1982) as the most plausible explanation of these changes. This theory claims that actual land rent in inner city neighbourhoods dominated by low-income families tends to be quite modest whereas the potential rent that the same areas can command is relatively high. In Smith's account (1982), upperincome individuals accordingly seize on the opportunity to turn these potential values into actual gains by redeveloping and occupying properties within the inner city. In so far as it goes, this theoretical description of gentrification probably captures part of the process, especially in its early stages, but it can only be partially true at best since it overlooks two crucial questions: Why did lowincome residents dominate these locations for so long despite their hypothesized high potential rents? As a corollary, what accounts for the precise historical timing of gentrification? These crucial questions can only be dealt with when we revise the rent-gap theory so as to accommodate the factor of locational change in intra-urban employment patterns as described earlier. Of course, gentrification was first observed in London by Glass (1964) more than half-a-century ago, long before cognitive-cultural capitalism had started to make its decisive entry on the scene. However, this apparent historical inconsistency with the analysis proposed here can plausibly be accounted for by reference to the post-War growth of London as a major international financial and commercial centre leading to this early expansion of housing demands in the inner boroughs by a well-heeled workforce. London thus appears to have been a precocious but explicable 
forerunner of trends that became much more pervasive towards the end of the twentieth century.

Merrifield (2014) has used the felicitous phrase "neo-Hausmannization" to refer to gentrification and its associated syndrome of exacerbated socio-economic bifurcation in the city. Indeed, in parallel with the case of Paris in the mid-nineteenth century, upgrading of the physical fabric of central areas of the city in cognitive-cultural capitalism has recreated many old urban injustices in new guises, notably the disproportionate burden of social and economic costs that has been thrust on low-income renters who can easily be ejected from properties destined for redevelopment. At the same time, the social fabric of those low-income neighbourhoods that remain in inner-city areas has been subject to erosion as a result of the growth of employment in central business districts and persistent gentrification, thereby further undermining the viability of these neighbourhoods as foci of family life and social reproduction for less privileged members of urban society. These continuing socio-spatial disruptions are amplified by the proliferation of gated communities in contemporary cities in flagrant repudiation of the intrinsically collective order of urban space. The net effect of this overall developmental model as it has unfolded in the most advanced cities of cognitive-cultural capitalism in the twenty-first century is the remarkable contrast between the glamour and extravagance of their most opulent sections and the squalor of their darker underbellies (Currid-Halkett and Scott, 2013).

The inequities of large cities assume different forms at different times but they are an intrinsic component of urban realities in all versions of capitalism, and, as noted, they remain very much part of the urban question today. As Harvey (2012) shows, these inequities lead systematically to political pressures that function as flash-points of social protest. Concomitantly, overt demonstrations of urban discontent are ready to burst forth over and over again into the streets of the city, as represented in the very recent past by the Occupy Movement that emerged on the heels of the recent financial and housing crisis. These demonstrations are usually tilted towards the redress of genuine injustices, but there has also been a troubling recrudescence of more regressive protest movements and violence in advanced capitalist cities of late, more often than not in some direct or indirect relation to the increasing ethnic and cultural diversity of urban social life as global capitalism runs its course. Two illustrations of this trend are the Pegida Movement that has recently come to the surface in Germany, and the widening jihadist threat in European cities. By its very nature, urbanization can always be counted on to generate and magnify expressions of political dissatisfaction, if only because it entails conspicuous social and economic differences between individuals who live together under conditions of extreme proximity, density, and interaction. The city, in brief, offers an opportune environment for the propagation of social passions and a ready-made stage for the mobilization of political energies whatever their inner motivation. 


\section{THE URBAN COMMON}

We have already seen that the city is the site of an enormous Common comprising a multitude of heterogeneous phenomena ranging from simple landuse externalities, through urban-wide agglomeration economies, to the intangible epistemic and cultural resources embedded in the urban milieu generally. Obviously, with the development of cyberspace, the scalar dimensions of many (but by no means all) segments of the Common now extend far beyond any single urban area and in numerous instances are nothing less than global. More accurately, perhaps, we should say that as cyberspace develops, the Common takes on the shape of a global network punctuated by strong localized articulations coinciding above all with major global cities.

Mainstream economics refers to the assets and liabilities that make up the contents of the Common as cases of "market failure," signifying that they are not internalized within private property arrangements and are not susceptible to exchange on competitive markets. This terminology, however, grants far too much, by implication, to the market as a normative ideal of social organization. The Common does not stand simply as a collection of aberrant or abnormal secondary outcomes relative to the market. Rather, it is a complementary form of social reality that is subject to its own specific structural logics and that produces its own specific kinds of effects. To be sure, these logics are not always fully rational in social terms, as the classical case of overgrazing on the village common lands in pre-industrial Britain makes clear. More generally, while the Common usually offers public benefits, it also sometimes imposes politically unacceptable costs on urban society, and sometimes holds potential assets that cannot be fully harvested in the absence of appropriate action. When conditions like these become critical, agencies with responsibilities for collective management and coordination will typically seek to impose remedial measures. Much of contemporary urban planning and policy can be understood as a response to predicaments of these sorts, as, for example, where collective action is called for to control harmful externalities (such as pollution) or to promote development (e.g. by ensuring more orderly production of agglomeration economies). By the same token, privatization is by no means the only way of responding to the problems of the urban Common, and in many cases is not even technically feasible.

Already, in the cities of nineteenth century industrial capitalism numerous problems pertaining to the Common were clearly apparent. In the burgeoning manufacturing centres of nineteenth century America and Europe, above all, malfunctions of the Common were a frequent occurrence. Breakdowns in regard to the physical and social environment (residential neighbourhoods, transport systems, public health, land use conflicts, and so on) not only threatened the competitive advantages of cities but also imposed heavy costs on individual workers and families. The challenges posed by these early manufacturing centres were not limited to the purely material aspects of urban life, for they also related to important facets of human consciousness and behaviour, and hence had an 
important bearing on the smooth adaptation of workers to the conditions of industrial-urban existence. The Common was deeply implicated in this matter. Factory owners in particular were vociferous about the deleterious influence of the social atmosphere of cities on workers' conduct and factory discipline. Marx wrote in several texts about this question and about the difficulties faced by capitalists in securing the subsumption of workers into the constraints and rhythms of the factory. Indeed, the stubbornness of the problems of large industrial centres in the nineteenth century induced many individual capitalists to seek out alternative models of urban work and life by establishing planned factory towns where they could free themselves from the irrationalities of unrestrained urbanization processes and exert monopoly control over the urban environment and simultaneously supervise the conduct of their workers. Paternalistic capitalists like Robert Owen, Sir Titus Salt, and George Pullman, for example, enthusiastically pursued this course of action by setting up factories and adjacent workers' settlements in New Lanark, Saltaire, and Pullman, respectively. However, this privatized approach to questions of defective urban development and the domestication of the human animal in nineteenth century capitalism could never become a society-wide solution if only for the evident reason that agglomeration processes operate with such force in market-based, competitive systems of production. As Benevolo (1971) has shown, modern town planning emerged as a means of at least partially taming the chaos of spontaneous urbanization in capitalism and of securing the social value of the Common.

Even today, the Common continues to exert considerable effects on patterns of socialization and habituation among the citizenry. Hardt and Negri (2009) have argued that the growth of the Common over the twentieth century and into the twenty-first has proceeded to the point where it has now steadily and inexorably become implicated in biopower relations across the whole of advanced capitalist society. Of course, this extension of the Common derives in important ways from modern media and information flows whose range far exceeds the bounds of the urban. But these biopower relations are also deeply rooted in the modern city, which, to paraphrase Hardt and Negri (2009), has become a site of human subsumption that complements and extends the disciplining influence of the workplace. The city shapes the life-world of the great majority of the citizenry through the ordered rhythms and routines of daily existence and the habituated responses that ensure its systematic operation. Accordingly, the mediatic environment, the workplace, and the city act - imperfectly but powerfully -- as mutually reinforcing instruments of social consent. The fact that the contents of the media derive so frequently from the cognitive-cultural industries that themselves are an integral part of the new urbanization almost certainly imparts a degree of consistency to their essential meanings. Indeed, much if not most of the culture we consume these days is produced by capitalist firms in the guise of profit-earning commodities. This contention is not intended to resuscitate the old nightmare script of the Frankfurt School with its claims about the wholesale stupefaction of the working class by means of the knowing manipulation of 
popular culture by capitalist enterprise. It does, however, point to some of the historically-constructed conditions that help to bring work, life, and consciousness in cognitive-cultural capitalism into some sort of effective alignment and that facilitate the formation of tacit acquiescence to the broad architecture of prevailing social arrangements (Peters and Bulut, 2011). There is every reason to suppose that the urban dimensions of this alignment will further stabilize as embedded sensors and information-gathering agencies in the digital city increase their monitoring of huge swaths of urban existence while at the same time pumping more and more data into the Common (Rabari and Storper, 2015). These developments will not only make it possible to boost the efficiency of urban public services, but also and more ominously perhaps to facilitate mass surveillance in the city.

At the same time, we must acknowledge the contradictory role of the Common not only as an instrument of biopower, but also as a source of new ideas and trends. However, in the core cities of cognitive-cultural capitalism, this role is almost always directed to pragmatic ends focused on innovation as a means of promoting competitive advantage. Hall (1998) has shown in considerable detail that urban areas have invariably been concentrated foci of innovative impulses, and the cities of cognitive-cultural capitalism appear to be unusually well endowed with the capacity to generate new economic opportunities. This predisposition ranges from the inventive dynamism of advanced high-technology industrial districts to the creative capacities of many cultural industry clusters in the large cosmopolitan centres of the global economy. These kinds of situations are related to the abundance of information and modish ideas (in varying states of systematization) that circulate freely through urban space, but they are in a more fundamental sense a reflection of the peculiar status of the city as a dense integrated grid of stimuli and responses, or what we might call a "creative field." In other words, the city operates like a vast communications network whose operational nodes coincide with individual workers, units of production, business associations, educational institutions, NGOs, municipal agencies, cultural infrastructures, and the like, all caught up with one another in structured interactions that pass through the Common and that sometimes result in concrete innovations.

This latter aspect of the city has taken on some importance in cognitive-cultural capitalism, where systematic ecologies of innovation rooted in the creative field (as in the classic case of Silicon Valley) have come in part to displace the old top-down fordist model of R\&D-based innovation. This shift has stimulated much recent research into the creative potentials of cities, with the currently fashionable theory of the "creative city" being one of its more conspicuous recent declinations. This theory has evolved in significant ways out of a vision of the city, formulated originally by Richard Florida (2004), as a privileged playground of the "creative class." Florida's definition of this class (i.e. all individuals with a bachelor's degree or better) is in some respects convergent with that of the highlevel cognitive-cultural workforce as identified in the present paper. The central 
thesis of the vision is that members of the creative class can be induced to migrate to cities by means of public investments in cultural and leisure amenities of various kinds, and that this will lead on to superior developmental outcomes in economic and cultural life. Proponents of the theory claim that it offers a powerful antidote to urban decline. However, as numerous critics have pointed out, its superficial plausibility dissolves away in the face of the unwarranted privilege that it accords to amenities (as opposed to jobs) in influencing the migratory movements of high-level cognitive-cultural workers (cf. Scott, 2014). Certainly, there are genuine analytical puzzles in regard to the creative potentials of cities, but these can never be adequately assessed without considered evaluation of local production capacities and the prospects for employment of suitably qualified workers. Creative city theory has attracted much attention, and large numbers of the urban elite all around the world have claimed it as their own, not only because of its cheerful (but questionable) theoretical claims and the city-marketing rhetoric that it provides, but also perhaps on account of the manner in which it covertly legitimizes the reallocation of urban public spending in ways that are congenial to the interests of those in the upper reaches of urban society (cf. Kraftl, 2014). Understandably, no popular political movement to date has sought to mobilize the citizenry under the banner of this vision.

\section{FINALE: THE CITY IN COGNITIVE-CULTURAL CAPITALISM}

The argument developed in these pages presents a picture of the city in capitalism as a spatial entity that emerges in the first instance as an agglomeration of production activities together with local labor market structures and a variegated palette of residential neighbourhoods. This constellation of land uses and human interactions is actively moulded by three main lines of force, namely, (a) individual firms and households whose actions are in important ways shaped by markets, (b) agencies of collective action that provide coordination and management services in the interests of urban viability, and (c) a Common composed of public assets, liabilities, and cultural resources that remain external to the market but are of great significance to the viability and livability of the city. These building blocks provide a generic language of urban analysis in capitalism, though their specific substantive logic and empirical expressions vary considerably from one historical and geographic situation to the next. Consider, again, the cities of cognitive-cultural capitalism in comparison with those of the fordist period. Patterns of urbanization in these two cases differ dramatically in regard to modalities of economic production, organization and the division of labor. Their dominant forms of social stratification and residential space deviate sharply as well. Additionally, the urban Common is probably now more extensive and variegated than it was in fordism while it has also become more closely implicated in the biopolitical power relations of capitalism. And whereas agencies of collective coordination and management in the city are still dominated by municipal government, a vast diversity of civil groups (such as 
business organizations or neighbourhood associations) providing specialized forms of social regulation are now increasingly intruding in both major and minor ways into the affairs of large metropolitan areas.

The manifestly short period of historical time during which the development of the cognitive-cultural city has come about means that anticipations in regard to future developments are liable to be especially untrustworthy, and this in its turn makes political advocacies doubly hazardous. In the light of the foregoing analysis, however, three outstanding issues call urgently for immediate attention while helping to point the way towards a politically-progressive alternative vision of the city in cognitive-cultural capitalism. First, then, as demonstrated here, the cognitive-cultural economy in major cities is associated with the resurgence of a host of specific externality effects - above all, agglomeration economies of scale and scope -- with major impacts on localized competitive advantage. The evident deduction is that very much more effective urban governance arrangements are required in order to ensure that the quantity and quality of these effects are optimized as far as possible. Second, as cognitivecultural capitalism has tightened its hold over major world cities and as the restructuring of social life in these cities has moved ahead, a significantly deepening bifurcation of incomes and life chances has also occurred. In contrast to this trend, the demands of democratic even-handedness and social justice suggest that the rewards and penalties of life in the city must be radically redistributed. A due regard for the likelihood of damaging urban disruptions arising out of this bifurcation also points to this policy goal. Third, the competitive temper of these cognitive-cultural times is an ideal breeding ground for the possessive individualism and narcissism that appear to be rampant in cities today. Castells (2013) has made the related remark that interrelationships between urban dwellers are becoming more and more depersonalized as webbased exchanges substitute to an ever growing extent for direct social interaction. Hence, despite the theoretical claims made in some quarters to the effect that the so-called creative class thrives on urban milieux where tolerance, openness, and social diversity are prominent, it is probably more accurate to say that any preferences of this sort, to the degree that they really exist, are more apt to be a reflection of indifference as opposed to forthright social engagement. The recovery of more immediate forms of social cohesion together with the consolations and pleasures of community is therefore also an important desideratum in any reform of the city in the interests of more meaningful and rewarding modalities of urban existence.

All that being said, the transcendence of capitalism and the advent of a future collaborative society alleged by Rifkin (2014) and others to be imminently in the offing -- at whatever spatial scale we care to imagine -- remains far from assured. If the arguments in the present paper are correct, the current situation is one where important shifts in social organization and many potential advances in the quality of work and life in cities are occurring, but the atrophy of capitalist social and property relations does not look as if it might be among them. 


\section{REFERENCES}

Allen, G.C., 1929. The Industrial Development of Birmingham and the Black Country. Hemel Hempstead: Allen and Unwin.

Benevolo, L., 1971. The Origins of Modern Town Planning. Cambridge, MA: MIT Press.

Benkler, Y., 2003. Freedom in the commons: towards a political economy of information. Duke Law Journal, 52(6), pp.1245-1276.

Castells, M., 2013. The impact of the Internet on society: a global perspective. In: F. González, ed. 2014.Ch@nge: 19 Key Essays on How Internet is Changing our Lives. Bilbao: BBVA. pp.132-133.

Chamberlin, E., 1933. The Theory of Monopolistic Competition. Cambridge, MA: Harvard University Press.

Coin, F., 2013. Turning contradictions into subjects: the cultural logic of university assessment. Knowledge Cultures, 1(4), pp.142-166.

Currid-Halkett, E. and Scott, A.J., 2013. The geography of celebrity and glamour: reflections on economy, culture, and desire in the city. Cities, Culture and Society, 4(1), pp.2-11.

Feldman, M.P. and Florida, R., 1994. The geographic sources of innovation: technological infrastructure and product innovation in the United States. Annals of the Association of American Geographers, [e-journal] 84(2), pp.210 - 227. http://dx.doi.org/10.1111/j.1467-8306.1994.tb01735.x.

Florida, R., 2004. Cities and the Creative Class. London: Routledge.

Fumagalli, A., 2011. Twenty theses on contemporary capitalism (cognitive biocapitalism). Angelaki: Journal of Theoretical Humanities, 16(3), pp.7-17.

Glass, R., 1964. London: Aspects of change. In: L. Less, T. Slater and E. Wyly, eds. 2013. The Gentrification reader. The Centre for Urban Studies. Aspects of Change. London: Routledge Taylor and Francis Group. pp. vii-ix.

Gouldner, A., 1979. The Future of Intellectuals and the Rise of the New Class. New York: Seabury.

Haase, A., Kabisch, S., Steinführer, A., Bouzarovski, S., Hall, R. and Ogden, P., 2010. Emergent Spaces of Reurbanisation: Exploring the Demographic Dimension of Inner-city Residential Change in a European Setting. Population Space And Place, [e-journal] 16(5), pp.443 - 463. http://dx.doi.org/10.1002/psp.603.

Hall, P., 1998. Cities in Civilization. New York: Pantheon.

Hardt, M. and Negri, A., 2009. Commonwealth. Cambridge, MA: Belknap Press. 
Harvey, D., 1978. The urban process under capitalism: a framewok for analysis. International Journal of Urban and Regional Research, [e-journal] 2(1-4), pp.101 - 131. http://dx.doi.org/10.1111/j.1468-2427.1978.tb00738.x.

Harvey, D., 2012. Rebel Cities. London: Verso.

Kraftl, P., 2014. Liveability and urban architectures: mol(ecul)ar biopower and the 'becoming lively' of sustainable communities. Environment and Planning D: Society and Space, [e-journal] 32(2), pp.274 - 292. http://dx.doi.org/10.1068/d21012.

Merrifield, A., 2014. The New Urban Question. New York: Pluto Press.

Moulier Boutang, Y., 2007. Le Capitalisme Cognitif, Comprendre la Nouvelle Grande Transformation et ses Enjeux. Paris: Editions Amsterdam.

Ó'hUallacháin, B., 1999. Patent places: size matters. Journal of Regional Science, [e-journal] 39(4), pp.613 - 636. http://dx.doi.org/10.1111/00224146.00152.

Ostrom, E., 2010. Beyond markets and states: polycentric governance of complex economic systems. American Economic Review, [e-journal] 100(3), pp.641 - 672. http://dx.doi.org/10.1257/aer.100.3.641.

Peters, M.A. and Bulut, E., 2011. Introduction: cognitive capitalism, education, and the question of immaterial labor. In: M.A. Peters and E. Bulut, eds. 2011. Cognitive Capitalism, Education and Digital Labor. New York: Peter Lang. pp. $\mathrm{xxV}-\mathrm{xl}$.

Rabari, C. and Storper, M., 2015. The digital skin of cities: urban theory and research in the age of the sensored and metered city, ubiquitous computing and big data. Cambridge Journal of Regions, Economy and Society, [e-journal] 8, pp.27 - 42. http://dx.doi.org/10.1093/cjres/rsu021.

Rifkin, J., 2014. The Zero Marginal-Cost Society. New York: Palgrave Macmillan.

Scott, A.J., 2011. Emerging cities of the third wave. City: Analysis of Urban Trends, Culture, Theory, Policy, Action, [e-journal] 15(3-4), pp.289 - 321. http://dx.doi.org/10.1080/13604813.2011.595569.

Scott, A.J., 2012. A World in Emergence: Cities and Regions in the 21st Century. Cheltenham: Edward Elgar.

Scott, A.J., 2014. Beyond the creative city: cognitive-cultural economy and the new urbanism. Regional Studies, [e-journal] 48(4), pp.565 - 578. http://dx.doi.org/10.1080/00343404.2014.891010.

Scott, A.J. and Storper, M., 2015. The nature of cities: the scope and limits of urban theory. International Journal of Urban and Regional Research, [e-journal] 39(1), pp.1 - 15. http://dx.doi.org/10.1111/1468-2427.12134. 
Sklair, L., 2010. Iconic architecture and the culture-ideology of consumerism. Theory, Culture and Society, [e-journal] 27(5), pp.135 - 159. http://dx.doi.org/10.1177/0263276410374634

Smith, N., 1982. Gentrification and uneven development. Economic Geography, 58(2), pp.139-155.

Standing, G., 2011. The Precariat: The New Dangerous Class. London: Bloomsbury.

Taylor, P.J., Derudder, B., Hoyler, M. and Ni, P., 2013. New regional geographies of the world as practised by leading advanced producer service firms in 2010. Transactions of the Institute of British Geographers, [e-journal] 38(3), pp.497 - 511. http://dx.doi.org/10.1111/j.1475-5661.2012.00545.x.

Vercellone, C. and Negri, T., 2008. Le rapport capital/travail dans le capitalisme cognitif. Multitudes, 32, pp.39-50.

Whyte, W.H., 1957. The Organization Man. Garden City: Doubleday.

\section{ABOUT THE AUTHOR}

Allen J. Scott is Distinguished Research Professor in the Department of Geography and the Department of Public Policy at the University of California -Los Angeles. His research is focused on issues of regional development, urbanization, and the cultural economy. His latest book is World in Emergence (Elgar, 2014). 